\title{
Assessing the Surveillance System for Priority Zoonotic Diseases in the Democratic Republic of the Congo, 2017
}

\author{
Kristen B. Stolka, Bonaventure Fuamba Ngoyi, Kathyrn E. L. Grimes, Jennifer J. Hemingway-Foday, \\ Leopold Lubula, Alain Nzanzu Magazani, Joseph Bikuku, Mathias Mossoko, \\ Leonie Manya Kitoto, Sylvie Mpangi Bashilebo, Dieudonné Lufwa Maya, \\ Benoit Kebela Ilunga, Sarah Rhea, and Pia D. M. MacDonald
}

High-functioning communicable disease surveillance systems are critical for public health preparedness. Countries that cannot quickly detect and contain diseases are a risk to the global community. The ability of all countries to comply with the International Health Regulations is paramount for global health security. Zoonotic diseases can be particularly dangerous for humans. We conducted a surveillance system assessment of institutional and individual capacity in Kinshasa and Haut Katanga provinces in the Democratic Republic of the Congo for nationally identified priority zoonotic diseases (eg, viral hemorrhagic fever [VHF], yellow fever, rabies, monkeypox, and influenza monitored through acute respiratory infections). Data were collected from 79 health workers responsible for disease surveillance at 2 provincial health offices, 9 health zone offices, 9 general reference hospitals, and 18 health centers and communities. A set of questionnaires was used to assess health worker training in disease surveillance methods; knowledge of case definitions; availability of materials and tools to support timely case detection, reporting, and data interpretation; timeliness and completeness of reporting; and supervision from health authorities. We found that health workers either had not been recently or ever trained in surveillance methods and that their knowledge of case definitions was low. Timeliness and completeness of weekly notification of epidemic-prone diseases was generally well performed, but the lack of available standardized reporting forms and archive of completed forms affected the quality of data collected. Lessons learned from our assessment can be used for targeted strengthening efforts to improve global health security.

Keywords: Zoonotic diseases, the Democratic Republic of the Congo, Viral hemorrhagic fever, Communicable diseases, Health workers, Surveillance, Outbreaks

Kristen B. Stolka, MPH, is a Research Public Health Analyst; Bonaventure Fuamba Ngoyi, MD, MPH-FELTP, is a Surveillance Officer; Kathyrn E. L. Grimes, MPH, is a Research Public Health Analyst; Jennifer J. Hemingway-Foday, MPH, is a Research Epidemiologist; Sarah Rhea, DVM, PhD, is a Research Epidemiologist; and Pia D. M. MacDonald, PhD, CPH, is a Senior Epidemiologist; all in Biostatistics and Epidemiology, RTI International, Durham, North Carolina. Leopold Lubula, MD, MPHFELTP, is a Surveillance Manager; Alain Nzanzu Magazani, MD, MPH-FELTP, is a Technical Expert; Joseph Bikuku, MD, MPH, is a Technical Expert; Mathias Mossoko, MSc, is an Epidemiologist and Data Manager; Leonie Manya Kitoto, MD, MPH, is a Technical Expert; Sylvie Mpangi Bashilebo, MSc, is an Epidemiologist and Surveillance Supervisor; Dieudonné Lufwa Maya, MD, $\mathrm{MPH}$, is a Database Analyst; and Benoit Kebela Ilunga, MD, MPH, is Director; all in the Directorate of Disease Control, Ministry of Public Health, Kinshasa, Democratic Republic of the Congo. 
I N TODAY'S INTERDEPENDENT GLOBAL ECONOMY, people and resources move quickly and easily across borders, resulting in an increased risk of rapidly spreading epidemic-prone diseases and public health emergencies of international concern. The Democratic Republic of the Congo (DRC), a hot spot of emerging zoonotic diseases and at high risk of future disease outbreaks, has experienced the emergence and reemergence of diseases such as Ebola and monkeypox with epidemic potential. ${ }^{1-4}$ In the DRC, many people live in tropical or heavily forested areas and frequently handle and consume bush meat-2 factors that increase the risk of being infected with a zoonotic disease. The prevention and control of highly epidemic zoonotic diseases is an international priority for global health security and a key component of the Global Health Security Agenda (GHSA). The GHSA sets a goal for all participating nations to identify the 5 zoonotic diseases or pathogens of greatest public health concern and strengthen existing surveillance systems for those diseases.

Like many low-resource African nations, the DRC's health system suffers from poor healthcare coverage, lack of needed infrastructure and equipment, insufficient human resources, stock-outs of essential medications and vaccines, and financial issues. ${ }^{5}$ These factors impede the health system's ability to prevent and prepare for future disease outbreaks. The 2016-2020 National Health Development Plan (PNDS) ${ }^{5}$ provides a 5 -year operational outline for achieving the goals of the national strategy for health system strengthening. The plan outlines the following 4 weaknesses for epidemiologic surveillance in the DRC: (1) problems with data completeness and promptness; (2) insufficient capacity for data analysis; (3) poor dissemination and lack of communication mechanisms; and (4) insufficient availability of computers and accessories (eg, printers) at the health zone level and in health facilities. To further national goals for strengthening epidemiologic surveillance, national and international disease surveillance stakeholders convened to draft the GHS 5-year roadmap, which aims to improve the DRC's ability to comply with the International Health Regulations (IHR) by identifying objectives and actions in line with the GHSA. ${ }^{6,7}$ The roadmap outlines priority country-specific objectives and milestones and identifies in-country partners capable of addressing those objectives.

The DRC health system is organized into 3 levels: national, intermediate, and peripheral. ${ }^{5}$ Below the national level, the intermediate health system level is comprised of 26 provincial-level administrative health offices and provincial hospitals. The peripheral level is subdivided into 518 health zones, each administered by a health zone office; 393 general reference hospitals; and 8,266 health centers. Health zones are further divided into health areas, with corresponding health centers responsible for disease surveillance and community health workers who support health system functions by reporting and referring suspect cases of epidemic diseases and unusual or unexpected health events in the community. The case-based surveillance system in the DRC is used to monitor the occurrence and spread of epidemic-prone diseases at each level of the health system. Health structures at each level conduct reporting of priority diseases and events of public health concern as defined by the DRC Technical Guide for Integrated Disease Surveillance and Response (IDSR). ${ }^{8}$

Routine weekly reporting occurs when the health zone level provides weekly aggregate case counts of the priority diseases for the preceding 7 days to the provincial level, which then reports it to the national level. When there is a suspected case of an epidemic-prone disease-in the community, via report from a community health worker, or within the health facility (eg, health center, general reference hospital)_health workers report the case immediately to the health zone office by telephone or by physical transport. After health zone authorities conduct an initial investigation to gather more information about the suspect case using the case investigation form, the health zone office notifies the provincial health office, which then notifies the Directorate of Disease Control (Direction de Lutte contre la Maladie, or DLM) at the national level. The role of the national level is then to ensure that the necessary resources, financial and logistical, are allocated to the provincial and health zone levels to facilitate a coordinated response to the outbreak.

To effectively implement GHS 5-year roadmap activities, an improved understanding of the strengths and weaknesses of the DRC case-based surveillance system was needed. To address this gap, we assessed the surveillance system in 2 provinces in the DRC using the US Centers for Disease Control and Prevention (CDC) guidelines for evaluating surveillance systems, including operations, resources, and attributes (eg, simplicity and data quality). We focused the surveillance system assessment on 5 priority zoonotic diseases selected by a multisectoral commission in 2016: viral hemorrhagic fever (VHF), yellow fever, rabies, monkeypox, and influenza monitored through acute respiratory infections. These 5 diseases were selected according to a scoring method that considered the severity, disease burden, transmission potential, laboratory diagnostic capability, prevention and control capability, and socioeconomic impact of the disease. In 2016, according to data collected and analyzed by the DLM, disease incidence (per 100,000 persons) was 0.01 for VHF, 3.56 for yellow fever, 0.13 for rabies, 3.90 for monkeypox, and 4,492.17 for acute respiratory infection. ${ }^{10}$

The objective of this assessment was to identify priority activities for zoonotic disease surveillance system strengthening. We shared and validated these results with the DLM and collaboratively developed an improvement plan that would identify specific activities that could be implemented to address the weaknesses in the zoonotic disease surveillance system. 


\section{Methods}

We conducted a surveillance system assessment of the 5 selected zoonotic diseases in 2 provinces of the DRC: Kinshasa and Haut Katanga. Our assessment targeted these 2 provinces because they were not included in a previous evaluation conducted by the DLM of 16 provinces at risk of Ebola in 2016. In addition, we planned to focus future surveillance system strengthening interventions in these locations, and therefore the assessment would serve as a baseline for measuring improvements.

The assessment instruments consisted of standardized questions to conduct interviews with selected health workers involved in epidemiologic surveillance activities at each level of the health system. The instruments covered the following topics: availability of appropriate operational guidelines and policies; health worker title, role, years of experience, education, and training; date of most recent training; availability of surveillance reporting tools, quality of data reported, and storage of completed reports; method of reporting (paper, electronic) and data transmission (in person, telephone, internet); data analysis meetings held and existence of epidemiologic data posted at the health structure; and health worker comments on ways to improve surveillance. The instruments were pretested with health workers from a health zone in Kinshasa not selected for the assessment, including 2 staff from the health zone office, 2 staff from a health center, and 2 community health workers. Data were collected in paper format, recorded into a Microsoft Excel spreadsheet, and analyzed with SPSS 22.0 software.

We assembled a field team of 6 people, led by a local field epidemiologist with experience conducting surveillance assessments and supported by national-level DLM staff. During March and April of 2017, the field team visited 38 sites throughout the health system in Kinshasa and Haut Katanga, including provincial health offices, health zone offices, general reference hospitals, and health centers (Table 1). The field team administered the questionnaire to 1 or 2 available health workers at each health structure who were responsible for case assessment, disease reporting, and data compilation.
To assess training level of staff in surveillance methods, we asked health workers if they had been trained in surveillance methods using the IDSR curriculum, which is offered by the ministry of health with support from the World Health Organization (WHO), and the Field Epidemiology Training Program (FETP), directed by the ministry of health with support from the CDC for either 3 months (Frontline FETP) or 2 years (Advanced FETP). If yes, the frequency and recency of training received was documented. Additionally, we asked community health workers if they had been trained in community-based surveillance methods.

Health worker knowledge of case definitions for the 5 priority zoonotic diseases was assessed by asking the respondent to list possible signs and symptoms of each disease, which the interviewer checked against standard and community-based case definitions as outlined in the IDSR guidelines for the $\mathrm{DRC}^{11,12}$ (Table 2). A percentage score was calculated out of the number of correct signs and symptoms listed for each disease. Supervision of health workers was assessed by asking respondents to indicate the number of supervision visits received by the superior health structure between October 2016 and December 2016.

Availability of required surveillance reporting tools was assessed by observing whether each type of blank form was available at each health structure. Among available and completed forms, the field team assessed data quality by determining whether the forms met the following data quality criteria: completeness of data entered (eg, zero reporting as applicable), void of erasures and crossed-out numbers, coherent figures and sums, and completeness of required information on the form (eg, name of health structure). To determine if health structures carried out a review and interpretation of data collected locally, we asked whether a data analysis meeting had been held at the health structure in the past 3 months and observed whether previous quarter epidemiologic data trends were posted to the wall of the health structure. Data compilation and storage were assessed by reviewing whether surveillance system reporting data were compiled at the health structure in (1) hardcopy paper format only, (2) electronic format only, or (3) both.

Table 1. Number of Health Structures Visited and Persons Interviewed by Health Structure and Province, March 2017 through April 2017

\begin{tabular}{lcccc}
\hline & $\begin{array}{c}\text { Kinshasa, } \\
\text { Persons } \\
\text { Interviewed }\end{array}$ & $\begin{array}{c}\text { Kinshasa, } \\
\text { Structures } \\
\text { Visited }\end{array}$ & $\begin{array}{c}\text { Haut Katanga, } \\
\text { Persons } \\
\text { Interviewed }\end{array}$ & $\begin{array}{c}\text { Haut Katanga, } \\
\text { Structures } \\
\text { Visited }\end{array}$ \\
\hline Provincial health office & 2 & 1 & 1 & 1 \\
Health zone office & 5 & 3 & 6 & 6 \\
Health center & 11 & 6 & 12 & 12 \\
General reference hospital & 4 & 3 & 6 & 6 \\
Community health worker & 9 & N/A & 23 & N/A \\
Total & 31 & 13 & 48 & 25 \\
\hline
\end{tabular}


Table 2. Signs and Symptoms of 5 Priority Diseases, according to standard and community-based suspect case definitions, used to determine respondent knowledge, March 2017 through April 2017

\begin{tabular}{|c|c|c|}
\hline Disease & $\begin{array}{c}\text { Standard Definition Signs } \\
\text { and Symptoms }\end{array}$ & $\begin{array}{c}\text { Community-Based Definition } \\
\text { Key Symptoms }\end{array}$ \\
\hline Viral hemorrhagic fever (VHF) & $\begin{array}{l}\text { - Sudden onset of fever } \\
\text { - Discomfort } \\
\text { - Generalized weakness } \\
\text { - Headache } \\
\text { - Pain in the limbs } \\
\text { - Anorexia } \\
\text { - Conjunctival injection }\end{array}$ & $\begin{array}{l}\text { - Fever } \\
\text { - Bleeding }\end{array}$ \\
\hline Rabies & $\begin{array}{l}\text { - Headache } \\
\text { - Nausea } \\
\text { - Fever } \\
\text { - Hydrophobia } \\
\text { - Anxiety } \\
\text { - Agitation }\end{array}$ & $\begin{array}{l}\text { - Fever } \\
\text { - Headache } \\
\text { - Hydrophobia } \\
\text { - Agitation }\end{array}$ \\
\hline Monkeypox & $\begin{array}{l}\text { - Sudden onset of fever } \\
\text { - Vesiculopustular eruption } \\
\text { - Lesions in the palms of the hands and soles of the feet }\end{array}$ & $\begin{array}{l}\text { - Fever } \\
\text { - Rash on hands and feet }\end{array}$ \\
\hline Yellow fever & $\begin{array}{l}\text { - Sudden onset of fever } \\
\text { - Jaundice within } 14 \text { days of onset of first symptoms } \\
\text { - All ages }\end{array}$ & $\begin{array}{l}\text { - Fever } \\
\text { - Jaundice }\end{array}$ \\
\hline Acute respiratory infection & $\begin{array}{l}\text { - Sudden onset of fever } \geq 38^{\circ} \mathrm{C} \\
\text { - Cough or sore throat } \\
\text { - All ages } \\
\text { - Death from unexplained respiratory disease }\end{array}$ & $\begin{array}{l}\text { - Cough or tingling of the throat } \\
\text { - Difficulty breathing with fever }\end{array}$ \\
\hline
\end{tabular}

This work did not require review by an Institutional Review Board because it is not defined as research according to federal regulations (45 CFR 46).

\section{REsUlts}

From March 2017 to April 2017, in Kinshasa and Haut Katanga provinces, the assessment team interviewed 47 health workers at 38 health structures-administrative structures (provincial and health zone offices) and health facilities (health centers and general reference hospitals) and 32 community health workers (Table 1). Types of health workers interviewed included health information officers, chief medical officers, medical officer in charge of disease surveillance, head physician, head nurse, and community health worker.

Kinshasa and Haut Katanga provinces are on opposite sides of the vast country of the DRC. Haut Katanga, home to Lubumbashi, the second largest city in the country and center of the copper mining industry in the DRC, is approximately 2,300 kilometers from Kinshasa province, location of the capital and DRC's largest urban center, with a population estimated at 13 million. The distance between the provincial health office and the furthest health zone office in Kinshasa is 150 kilometers, whereas the distance between the provincial health office and farthest health zone office in the larger and more rural province of Haut Katanga is 520 kilometers.

\section{Health Worker Surveillance Training}

We found that the most common type of training received among health worker respondents at health structures was IDSR training: $36 \%$ of health workers at administrative structures and $21 \%$ at health facilities had participated in an IDSR training at some point in the past. At administrative structures, 2 (14\%) respondents reported receiving FETP training. The majority (79\%) of health facility respondentsthose responsible for disease surveillance and diagnosis—did not report any formal or informal training specific to surveillance. However, $47 \%$ of community health workers reported that they had received community-based surveillance training (Table 3).

\section{Health Worker Knowledge of Case Definitions}

Overall, case definitions of the 5 priority zoonotic diseases were not well understood by the health workers interviewed (Table 4). Among administrative and facility-level health workers, only $7 \%$ and $12 \%$, respectively, could name at least 4 out of 7 signs and symptoms used in the standard case definition for VHF, whereas 59\% of community health workers could name at least 1 of the 2 key symptoms used in the community-based case definition of VHF. 
Table 3. Number and Percentage of Health Workers Trained in Surveillance Methods, by Type of Training Program and Health Level, March 2017 through April 2017

\begin{tabular}{lc}
\hline Type of Training & No. Trained (\%) \\
\hline Administrative structures $(n=14)$ & $5(36)$ \\
IDSR only & $2(14)$ \\
FETP only & $4(29)$ \\
Both IDSR and FETP & $3(21)$ \\
None & $7(21)$ \\
Health facilities $(n=33)$ & $0(0)$ \\
IDSR & $0(0)$ \\
FETP & $26(79)$ \\
Both IDSR and FETP & $15(47)$ \\
None & \\
Community $(n=32)$ & \\
Community-based surveillance & \\
\hline
\end{tabular}

Note. IDSR = Integrated Disease Surveillance and Response; FETP = Field Epidemiology Training Program.

Conversely, knowledge of yellow fever was highest among all of those interviewed, with $93 \%$ of administrative health workers and $91 \%$ of facility-level health workers able to name at least 2 out of 3 signs and symptoms used in the standard case definition for yellow fever.

\section{Supervision of Health Workers}

The low proportion of supervision visits received at each level of the health system indicates that fewer supervision visits took place than recommended. The health zone offices received $33 \%$ of expected supervision visits from the provincial level offices, the general reference hospitals received $67 \%$ of expected visits from the health zone offices, and the health centers received $56 \%$ of expected supervisions from the health zone offices (Table 5).

\section{Use of Surveillance Reporting Tools}

Not all required reporting tools were available at health facilities, and some facilities were using outdated reporting tools (Table 6). The rumor register, which documents unexplained or suspicious illnesses or deaths obtained from unofficial sources such as community members, media outlets, schools, or pharmacies, was available in the fewest health facilities, whereas the consultation register was available in all health facilities. The weekly notification form was available in all health zone offices, $83 \%$ of health

Table 4. Respondent Knowledge of Case Definitions of 5 Priority Zoonotic Diseases, Score of $\geq 50 \%$ by Respondent's Health Structure ${ }^{\mathrm{a}}$ and Disease, March 2017 through April 2017

\begin{tabular}{lrr}
\hline & Yes, No. (\%) & No, No. (\%) \\
\hline Administrative structures $(n=14)$ & $1(7)$ & $13(93)$ \\
VHF & $3(21)$ & $11(79)$ \\
Rabies & $9(64)$ & $5(36)$ \\
Monkeypox & $13(93)$ & $1(7)$ \\
Yellow fever & $11(79)$ & $3(21)$ \\
Acute respiratory infection & & \\
Health facilities $(n=33)$ & $4(12)$ & $29(88)$ \\
VHF & $11(33)$ & $22(67)$ \\
Rabies & $8(24)$ & $25(76)$ \\
Monkeypox & $30(91)$ & $3(9)$ \\
Yellow fever & $26(79)$ & $7(21)$ \\
Acute respiratory infection & & \\
Community $(n=32)$ & $19(59)$ & $13(41)$ \\
VHF & $10(31)$ & $22(69)$ \\
Rabies & $5(16)$ & $27(84)$ \\
Monkeypox & $18(56)$ & $14(44)$ \\
Yellow fever & $25(78)$ & $7(22)$ \\
Acute respiratory infection & & $(94)$ \\
\hline
\end{tabular}

${ }^{\text {a} A d m i n i s t r a t i v e ~ s t r u c t u r e ~ i n c l u d e s ~ p r o v i n c i a l ~ h e a l t h ~ o f f i c e ~ a n d ~ h e a l t h ~ z o n e ~ o f f i c e ; ~ h e a l t h ~ f a c i l i t i e s ~ i n c l u d e ~ h e a l t h ~ c e n t e r s ~ a n d ~ g e n e r a l ~ r e f e r e n c e ~}$ hospitals; and community includes community health workers. 
STOLKA ET AL

Table 5. Proportion of Planned Supervision Visits Received by Health Structure, October 2016 through December $2016^{\mathrm{a}}$

\begin{tabular}{lccr}
\hline Structure & Structures, No. & Planned, No. & Received, No. (\%) \\
\hline Provincial health office & 2 & 2 & $0(0)^{\mathrm{a}}$ \\
Health zone office & 9 & 9 & $3(33)$ \\
General reference hospital & 9 & 27 & $18(67)$ \\
Health center & 18 & 54 & $30(56)$ \\
\hline
\end{tabular}

${ }^{a}$ Assessment period (October 2016 through December 2016) did not cover the entire supervision period of 6 months; therefore, 1 of the 2 planned visits per provincial health office may still have occurred during the required period.

centers, but in only 2 out of 9 general reference hospitals. The case notification form was available in half $(50 \%)$ of health centers, and the case investigation form was available in only $22 \%$ of health centers.

\section{Data Quality and Analysis}

Findings indicate that $82 \%$ of the weekly notification forms at administrative structures were filled out completely (no missing fields) as compared to $48 \%$ of weekly notification forms at health facilities. Rates of correct completion of weekly notification forms were $55 \%$ in administrative structures and $33 \%$ in health facilities (Table 7). Common errors included incorrectly reporting the absence of disease cases by leaving the field blank rather than filling in zeros to indicate that no cases were reported and incorrectly calculated sums.

Both provincial health offices (100\%) and $70 \%$ of health zone offices reported conducting 1 surveillance data analysis meeting in the past 3 months. A quarter of health facilities $(26 \%)$ reported holding a data analysis meeting in the past 3 months. One provincial health office (50\%), 3 health zone offices $(33 \%)$, and 4 general reference hospitals and health centers $(13 \%)$ posted previous quarter epidemiologic data in a location that could be viewed by anyone visiting the health structure.

\section{Data Compilation and Storage}

Both provincial health offices (100\%) and 30\% of health zone offices reported compiling and storing data in electronic format (Microsoft Excel) or both hardcopy and electronic formats. With the exception of 2 hospitals in Kinshasa and 1 health center in Haut Katanga, the majority $(88 \%)$ of health facilities interviewed reported that they compiled data only in hardcopy paper format.

\section{Discussion}

The design of the case-based surveillance system in the DRC is consistent with IDSR guidelines and is well understood by health system actors; however, the capacity of health workers to adequately contribute to the system is affected by the low level of training in surveillance methods, low knowledge of case definitions, infrequent supervision from higher-level health authorities, and lack of surveillance reporting tools. Our assessment took place in 2 of the most populated provinces in the DRC, where healthcare personnel and resources would be expected to be most concentrated and of higher quality. This emphasizes the fact that the weaknesses observed in the surveillance system in this assessment may be even more pronounced in lowerresource and less populated areas in the DRC. These factors ultimately lead to inadequate quality and reporting of zoonotic disease surveillance data and the inability to interpret and present surveillance data at a local level, where disease outbreaks emerge. These weaknesses compound the DRC's high vulnerability to emerging zoonotic diseases and affect the country's ability to respond quickly to outbreaks. ${ }^{4}$

Although our sample of health structures and health workers is neither nationally nor internationally representative, the results of this assessment highlight the barriers to maintaining a globally responsive disease surveillance system in low resource countries. A strong and sustained commitment from government and international partners to an improved case-based surveillance system will ensure that epidemic-prone diseases are controlled within and beyond the borders of the DRC. This includes a sustained commitment to strengthening the surveillance system, including maintaining and growing the technical competence and motivation for the biosurveillance workforce.

Table 6. Proportion of Health Structures with Required Disease Surveillance Reporting Tools, March 2017 through April 2017

\begin{tabular}{lccc}
\hline & Health Zone Office $(\mathrm{n}=9)$, & General Reference Hospital $(\mathrm{n}=9)$, & $\begin{array}{c}\text { Health Center }(\mathrm{n}=18), \\
\text { No. }(\%)\end{array}$ \\
Reporting Tools & No. $(\%)$ & No. $\%)$ & $15(83)$ \\
Weekly notification form & $9(100)$ & $2(23)$ & $0(0)$ \\
Rumor register & $1(11)$ & $0(0)$ & $9(50)$ \\
Case notification form & $7(77)$ & $1(11)$ & $18(100)$ \\
Consultation register & NA & $9(100)$ & $4(22)$ \\
Case investigation form & $9(100)$ & $0(0)$ & \\
\hline
\end{tabular}


Table 7. Data Quality Criteria of Weekly Notification Form Met, by Health Structure, ${ }^{a}$ March 2017 through April 2017

\begin{tabular}{lcc}
\hline & Yes, No. (\%) & No, No. (\%) \\
\hline Administrative structures $(n=11)$ & $9(82)$ & $2(18)$ \\
Completely filled out & $5(45)$ & $6(55)$ \\
Void of erasures & $8(72)$ & $3(28)$ \\
With coherent data & $6(55)$ & $5(45)$ \\
Correctly filled out & & $14(52)$ \\
Health facilities $(n=27)$ & $13(48)$ & $15(56)$ \\
Completely filled out & $12(44)$ & $13(48)$ \\
Void of erasures & $14(52)$ & $18(67)$ \\
With coherent data & $9(33)$ & $(56)$ \\
Correctly filled out & & \\
\hline
\end{tabular}

${ }^{a}$ Administrative structure includes provincial health offices and health zone offices; health facilities include health centers and general reference hospitals; and community includes community health workers.

This assessment revealed that most health workers interviewed did not have formal training in epidemiologic surveillance, as evidenced by the lack of recent training in IDSR guidelines for both health workers at facilities and administrative structures. Those who reported ever having received IDSR training had not been trained in at least 3 years, indicating an urgent need for refresher training and more targeted supervision efforts. Implementation of regular and recurring training on updated IDSR guidelines for both new and existing health workers could reinforce principles and guidelines for disease surveillance at the facility level.

Health workers' low level of knowledge of signs and symptoms of VHF is a noteworthy weakness given the worldwide attention to the recent Ebola outbreak in West Africa and the continual reemergence of Ebola throughout the DRC since it was discovered in 1976, including the recent outbreaks in Likati health zone of Bas Uélé Province in May-June 2017** and Bikoro health zone of Equateur Province in May 2018.*** This may be because VHF historically has been found in forested areas in northern DRC (eg, Ebola outbreaks in Tshuapa and Bas Uélé provinces, DRC) rather than in Kinshasa and Haut Katanga provinces, where our assessment took place. Nevertheless, with the frequent travel of people from rural to urban areas and the potential rapid amplification of an Ebola outbreak in urban areas, this finding is noteworthy.

In addition, the VHF standard case definition includes nonspecific clinical symptoms such as fever, pain, and headache that may be associated with other conditions and may make them more difficult to recall, as compared to the other priority zoonotic diseases assessed, which had fewer and more clinically specific symptoms. However, knowledge of case definitions with nonspecific symptoms can be critical during an Ebola outbreak to ensure as many cases as possible are identified in a timely manner. Broader defini-

\footnotetext{
**http://www.who.int/emergencies/ebola-DRC-2017/en/

***https://reliefweb.int/sites/reliefweb.int/files/resources/SITREPEVD-DRC-20180511.pdf
}

tions are helpful to identify cases when epidemiologic risk factors are unknown (eg, contact with a confirmed case) and for diseases with highly specific symptoms that are rare or difficult to diagnose (eg, internal hemorrhage). ${ }^{13}$

Knowledge of the VHF community case definition was higher among community health workers than their facilitylevel counterparts. This could be because the VHF community case definition has fewer symptoms, making it easier to recall. Regardless, sufficient knowledge of VHF among community health workers is a positive finding, given that community engagement can be an important factor in fighting Ebola outbreaks. ${ }^{14,15}$ Ebola can incite fear and stigma in communities, causing potential cases to avoid health facilities, which can result in greater risk of transmission and death. ${ }^{14}$ Therefore, community health workers are an important first line of defense in detecting diseases like Ebola. Other studies in Africa have also found community health workers/volunteers to be valuable assets in the early detection of epidemic-prone diseases through basic syndromic surveillance. ${ }^{16,17}$

Recall of the case definition of yellow fever is the highest of the 5 zoonotic diseases assessed. The findings about yellow fever provide a realistic minimum target of what we can expect around the other diseases with additional training. There has been a recent outbreak of yellow fever that originated in Angola and spread across the border into provinces near Kinshasa in $2016,{ }^{18}$ which could contribute to the higher recall among health workers, particularly in Kinshasa province. However, in contrast to the VHF standard case definition with 7 signs and symptoms, the yellow fever case definition contains 3 signs and symptoms, which may also make it easier to recall in its entirety.

Our findings suggest that more training and reinforcement on case definitions is needed at all levels, but particularly for those who interact with patients in communities and at the lower levels of the health system. The DRC might consider training community health workers in communitybased surveillance methods, particularly in rural areas with poor access to formal healthcare structures. A focused training on community-based surveillance of the priority 
diseases could be combined with existing training of community health workers on vaccine-preventable childhood illnesses (eg, tetanus, meningitis, polio, diphtheria, and measles) currently offered by the WHO. Another recommendation that has been made in similar settings is to reinforce surveillance resources or implementation of sentinel surveillance sites in geographic areas that experience repeat outbreaks of epidemic-prone diseases. ${ }^{17}$

In addition to the lack of adequate training in surveillance methods, the inconsistent compilation and insufficient archiving of surveillance data impedes the ability of health workers to analyze and interpret facility-level surveillance data. Most health structures, except for the provincial health office, maintained only recent paper hardcopies of surveillance reporting forms because of the lack of suitable storage for archived data. For example, surveillance reporting forms provided by the ministry of health have carbon copies that should be stored in secure, fire-proof cabinets at the reporting structure, organized according to epidemiologic week. The health zone offices are expected to use electronic reporting tools (eg, Excel spreadsheets) to enter weekly epidemiologic data and transfer data via the internet available through satellite installed at the structure, yet many health zone offices were still using paper hardcopies only and either calling in or physically delivering the reports to the provincial health office. This is primarily because computers and communication satellites are either not available or not wellfunctioning, or health workers are required to use their personal phones and computers.

Without archived surveillance data at the health structure, review and interpretation of surveillance data rarely take place and surveillance data from the previous quarter were rarely displayed on the wall of health structures as recommended for transparent data sharing among staff, patients, and surveillance stakeholders. Future assessments may also want to observe and assess whether materials needed for data sharing and dissemination, such as paper, flip charts, markers, rulers, and tape, are available at health structures and provided by higher-level health authorities. Furthermore, surveillance data compiled in different formats and transmitted via multiple methods can lead to confusion and inaccuracy in reports sent to the higher-level health authorities. ${ }^{19}$

The weekly notification form was available in nearly all health zone offices and the majority of health centers but found in fewer than a quarter of general reference hospitals. A prior evaluation conducted by the DLM in other provinces revealed similar gaps in the availability of required surveillance tools in hospitals in the DRC (written communication, DLM). It is a troubling finding that these higher-level structures are not adequately integrated into the surveillance system. Moreover, the head nurse is often the only health worker trained and responsible for surveillance at the hospital level, and if he or she is absent or busy with clinical care, disease reporting does not occur in a timely manner. Reporting of notifiable diseases is less of a priority in health structures that do not have a designated surveillance officer. ${ }^{20}$

We found that even when surveillance reporting tools were available, data quality concerns remained. Administrative structures were more likely to have weekly notification forms that met data quality criteria for completeness and coherence of data compared to health facilities. Administrative structures compile and aggregate data received from lower-level health facilities. If administrative structures detect any errors or omissions, they attempt to contact the health facilities to confirm or verify information before reporting the data to the national level. It is likely that the original data source at the health facility is not corrected at the same time, which may be the reason we see lesser quality data at the lower levels. Incomplete data could also be explained by the use of outdated weekly notification forms; therefore, we recommend that the ministry of health conduct an assessment and inventory of forms and print and distribute updated forms nationwide as needed.

The limitations of our assessment include the fact that most data were collected from respondent recall, creating a potential recall bias. The field team attempted to verify responses by reviewing documentation at the health structure when available. However, in many cases, archived forms were unavailable, and documentation and dates of supervision visits and data analysis meetings were missing. This assessment took place in 2 of the 26 provinces in the DRC, and thus the findings are not generalizable to the entire country. However, these findings are consistent with a surveillance evaluation conducted in 2016 at health structures in 16 provinces of the DRC, providing further evidence that the surveillance system weaknesses are widespread (written communication, DLM).

\section{RECOMMENDATIONS}

Based on these assessment results, we worked with national surveillance partners to develop an improvement plan for surveillance system strengthening in the DRC. The improvement plan documented significant weaknesses in the surveillance system and described specific, high-impact activities to target those weaknesses. Recommendations stemming from this assessment were organized into 3 strategic areas: (1) strengthen systems for collecting and analyzing surveillance data, (2) strengthen information systems and reporting, and (3) strengthen health worker capacity and provision of materials.

Several cross-cutting activities were suggested to enhance surveillance of priority zoonotic diseases:

1. To improve completeness and data quality, ensure updated surveillance forms are available at all reporting structures and organize a refresher training for health workers on how to fill out required forms. 
2. To improve data analysis capabilities, develop a checklist to use during data analysis meetings to help identify problems, and conduct a training session on the use of data analysis tools such as Excel and EpiInfo.

3. To improve supervision, allocate additional financial and logistical resources to ensure supervision is conducted at each level, and develop improved strategies, tools, and indicators to help health workers recall case definitions and better measure health worker competencies.

4. Build capacity of health workers involved in the surveillance system to better detect, notify, and report priority zoonotic diseases, especially diseases with nonspecific signs and symptoms, such as VHF, to help improve identification of cases in the early stages of disease progression. This will require organized efforts to train more health workers in surveillance methods, especially at the hospital level, produce and distribute case definition job aids to health facilities, and conduct supervision visits in a timely and effective manner.

Surveillance system evaluations are important to assessing compliance with the IHR and provide data with which to measure progress from interventions aimed at strengthening surveillance systems. Moving forward with the recommendations identified here is contingent on the DRC having adequate financial and material resources to maintain basic functions in an already constrained health system. Increasing the capabilities of the surveillance system in the DRC is critical to health security in the DRC and the broader global community.

\section{ACKNOWLEDGMENTS}

The authors would like to acknowledge Dr. Joelle Kabamba and Dr. Abdou Salam Gueye for providing technical guidance in this surveillance assessment. This publication was supported by Cooperative Agreement Number 1U2GGH001722-01, funded by the Centers for Disease Control and Prevention. Its contents are solely the responsibility of the authors and do not necessarily represent the official views of the Centers for Disease Control and Prevention or the Department of Health and Human Services.

\section{REFERENCES}

1. Allen T, Murray KA, Zambrana-Torrelio C, et al. Global hotspots and correlates of emerging zoonotic diseases. Nat Commun 2017;8(1):1124.
2. Grard G, Biek R, Tamfum JJ, et al. Emergence of divergent Zaire Ebola virus strains in Democratic Republic of the Congo in 2007 and 2008. J Infect Dis 2011;204(Suppl 3): S776-S784.

3. Kantele A, Chickering K, Vapalahti O, Rimoin AW. Emerging diseases-the monkeypox epidemic in the Democratic Republic of the Congo. Clin Microbiol Infect 2016; 22(8):658-659.

4. Moore M, Gelfeld B, Okunogbe A, Paul C. Identifying future disease hot spots: infectious disease vulnerability index. Rand Health Q 2017;6(3):5.

5. Republique Democratique du Congo. Ministère de la santé publique. RDC Plan National de Developpement Sanitaire 2016-2020: Vers La Couverture Sanitaire Universelle; 2016. http://www.nationalplanningcycles.org/sites/default/files/ planning_cycle_repository/democratic_republic_of_congo/ pnds_2016-2020_version_finale_29_avril_2016.pdf. Accessed September 4, 2018.

6. Katz R, Sorrell EM, Kornblet SA, Fischer JE. Global Health Security Agenda and the International Health Regulations: moving forward. Biosecur Bioterror 2014;12(5):231-238.

7. World Health Organization. International Health Regulations; 2005. http://www.who.int/topics/international_health_ regulations/en/. Accessed September 4, 2018.

8. Republique Democratique du Congo. Ministère de la santé publique. Guide technique pour La Surveillance Integree de La Maladie et Riposte (SIMR). 2eme edition. 2011. https://www. afro.who.int/sites/default/files/2017-06/IDSR-Technical\%20 -Guidelines-2010_French\%20_final.pdf. Accessed September 4, 2018 .

9. German RR, Lee LM, Horan JM, et al. Updated guidelines for evaluating public health surveillance systems: recommendations from the Guidelines Working Group. MMWR Recomm Rep 2001;50(RR-13):1-35.

10. Direction de Lutte contre la Maladie (DLM). Rapport Triennal de Surveillance Des Maladies à Potentiel Épidémique En République Démocratique du Congo, 20142016. 2017b.

11. World Health Organization. Technical Guidelines for Integrated Disease Surveillannce and Response in the African Region. 2010. http://www.cdc.gov/globalhealth/healthprotection/ $\mathrm{idsr} / \mathrm{pdf} /$ technicalguidelines/idsr-technical-guidelines-2ndedition_2010_english.pdf. Accessed September 4, 2018.

12. World Health Organization. Surveillance Intégrée des Maladies et Riposte dans la Région Africaine: Manuel de Formation à la Surveillance à Base Communautaire. 2015. https://www. afro.who.int/sites/default/files/2017-06/surveillance-\%C3\%A0base-communautaire_idsr_manuel-de-formation.pdf. Accessed September 4, 2018.

13. Hsu CH, Champaloux SW, Keita S, et al. Sensitivity and specificity of suspected case definition used during West Africa Ebola epidemic. Emerg Infect Dis 2018;24(1):9-14.

14. Coltart CE, Lindsey B, Ghinai I, Johnson AM, Heymann DL. The Ebola outbreak, 2013-2016: old lessons for new epidemics. Philos Trans R Soc Lond B Biol Sci 2017;372(1721): 20160297. 
15. Nuriddin A, Jalloh MF, Meyer E, et al. Trust, fear, stigma and disruptions: community perceptions and experiences during periods of low but ongoing transmission of Ebola virus disease in Sierra Leone, 2015. BMJ Global Health 2018; 3(2): 000410

16. Ndiaye SM, Quick L, Sanda O, Niandou S. The value of community participation in disease surveillance: a case study from Niger. Health Promot Int 2003;18(2):89-98.

17. Sanchez-Padilla E, Carrillo-Santisteve P, Luquero FJ. Evaluation of the cholera surveillance system in Guinea Bissau. December 2009. WHO Collaborating Centre for Epidemiology Research and Response to Emerging Diseases. https://www. unicef.org/evaldatabase/files/GBIS-2010-001-1.pdf.

18. Otshudiema JO, Ndakala NG, Mawanda EK, et al. Yellow fever outbreak-Kongo Central Province, Democratic Republic of the Congo, August 2016. MMWR Morb Mortal Wkly Rep 2017;66(12):335-338.
19. Adokiya MN, Awoonor-Williams JK, Barau IY, Beiersmann C, Mueller O. Evaluation of the integrated disease surveillance and response system for infectious diseases control in northern Ghana. BMC Public Health 2015;15:75.

20. Weber BI. Evaluation of the Notifiable Disease Surveillance System in Gauteng Province, South Africa [master's thesis]. Pretoria: University of Pretoria; 2007. https://repository.up.ac. za/bitstream/handle/2263/26850/dissertation. pdf? sequence=1. Accessed September 13, 2018.

Address correspondence to: Kristen B. Stolka, MPH Research Public Health Analyst RTI International 3040 Cornwallis $R d$.

Rsearch Triangle Park, NC 27709

Email: kstolka@rti.org 